\title{
Comment on "A comparison of catchment travel times and storage deduced from deuterium and tritium tracers using StorAge Selection functions" by Rodriguez et al. (2021)
}

\author{
Michael Kilgour Stewart ${ }^{1}$, Uwe Morgenstern ${ }^{2}$, Ian Cartwright ${ }^{3}$ \\ $5 \quad{ }^{1}$ Aquifer Dynamics and GNS Science, PO Box 30 368, Lower Hutt 5040, New Zealand \\ ${ }^{2}$ GNS Science, PO Box 30 368, Lower Hutt 5040, New Zealand \\ ${ }^{3}$ School of Earth, Atmosphere and Environment, Monash University, Clayton, Vic 3800, Australia \\ Correspondence to: Michael Stewart (m.stewart@gns.cri.nz)
}

Abstract. The combined use of deuterium and tritium to determine travel time distributions (TTDs) in streams is an important development in catchment hydrology (Rodriguez et al, 2021). This comment takes issue with Rodriguez et al.'s general rejection of the truncation hypothesis, i.e. that the almost exclusive use of stable isotopes has truncated our vision of streamflow TTDs and caused us to miss the long tails of old water often shown by tritium. We discuss reasons why this hypothesis may not hold for the catchment described by Rodriguez et al. (2021), but could still apply to a large proportion of all catchments. We also discuss more generally future applications of tritium in northern and southern hemisphere catchments.

\section{Introduction}

Rodriguez et al. (2021) applied deuterium $\left({ }^{2} \mathrm{H}\right)$ and tritium $\left({ }^{3} \mathrm{H}\right)$ measurements to determine transit time distributions (TTDs) in a forested headwater catchment (the Weierbach Catchment in Luxembourg). They used the method of StorAge Selection (SAS) functions (Botter et al., 2011; Benettin et al., 2017) to transform the input (rainfall) values of the two tracers to match the concentrations of the tracers in the stream water draining the catchment also taking account of output via evapotranspiration. Then they tested the (truncation) hypothesis that the tritium TTD would extend to longer transit times than the deuterium TTD. They found that the TTDs were not different within error and concluded that "the stable isotopes do not seem to systematically underestimate travel times or storage compared to tritium".

The truncation hypothesis put forward by Stewart et al. (2010) states: "The use of stable isotope tracers $\left({ }^{2} \mathrm{H}\right.$ and $\left.{ }^{18} \mathrm{O}\right)$ and chloride $(\mathrm{Cl})$ more than any other tool has influenced the development of the field since their first use in the 1970s (Dinçer et al., 1970). [...] But what if the information gleaned from stable isotopes actually biased our understanding of how catchments store and transmit water? What if our now, almost exclusive use of stable isotopes has led us down a pathway that has skewed our view of streamwater residence time? Here we show [using tritium $\left({ }^{3} \mathrm{H}\right)$ ] that deeper groundwater contributes more to streamflow than we are able to ascertain using conventional stable isotope-based hydrograph separation and streamflow residence time approaches." 


\section{The Weierbach Catchment study}

The conclusion that no significant old water (beyond the range that can be resolved by stable isotopes) was identified by ${ }^{3} \mathrm{H}$ in the Weierbach Catchment stream does not mean that such old water does not exist in other catchments and therefore that the truncation hypothesis should be rejected for all catchments. In fact, there is

Northern Hemisphere precipitation was much more strongly affected by bomb tritium due to nuclear weapons testing in the 1950s than Southern Hemisphere precipitation (as shown by data in the WISER database of the International Atomic Energy Agency, IAEA and WMO, 2020). Fig. 1a shows the tritium record in precipitation from Trier, Germany in the Northern Hemisphere (Schmidt et al., 2020) with earlier records from Vienna, and later data). The Northern Hemisphere bomb peak was about 100 times bigger than the Southern Hemisphere bomb peak and was about two years earlier. The Trier record is the nearest to the Weierbach Catchment. 

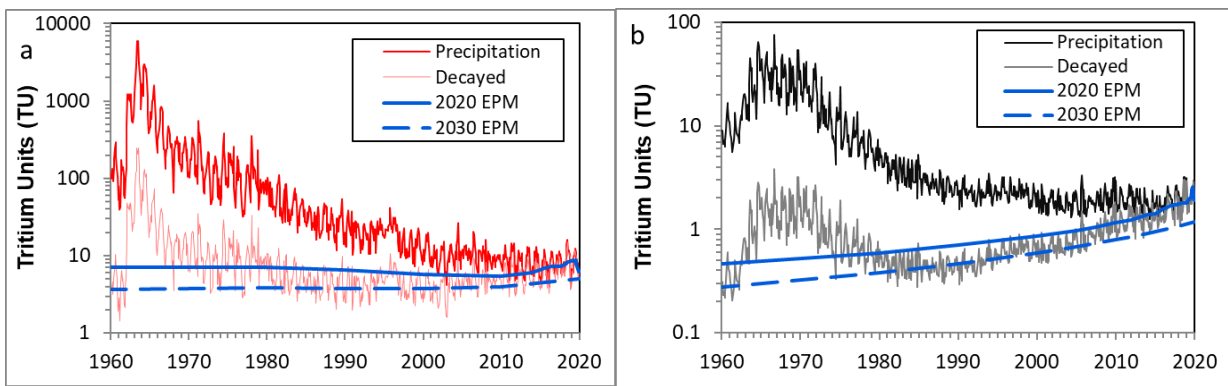

Fig. 1a. Tritium concentration in precipitation at (a) Trier/Vienna, and (b) Kaitoke, NZ, after accounting for radioactive decay up to 2020, and after mixing of the decayed concentrations using an $\mathrm{EPM}(\mathrm{f}=0.7)$ model (blue curves).

The figures also show the reductions in ${ }^{3} \mathrm{H}$ activities of the rainfall due to radioactive decay from the rain date to 2020 (curves marked "decayed"). These present-day ${ }^{3} \mathrm{H}$ activities of older water are lower than current rainfall except when they are affected by bomb tritium which peaked in the 1960s. However, water present in a stream or spring will have a wide spread of ages due to the flow processes in the soil and country rock. This mixing is simulated here by using the exponential piston flow lumped parameter model (EPM) with an exponential fraction $\mathrm{f}=0.7($ EPM ratio $=0.43)$. The blue mixing curves in Fig. 1 show the variations in ${ }^{3} \mathrm{H}$ with MTT expected for samples collected in 2020 and 2030. The $\operatorname{EPM}(\mathrm{f}=0.7)$ model is chosen here as a realistic mid-range estimate between the model with no mixing $(\operatorname{EPM}(\mathrm{f}=0)$, also called the piston flow model that would produce the radioactively decayed curves in Fig. 1) and the fully mixed model (EPM( $\mathrm{f}=1)$, also called the exponential model). Other lumped parameter models such as the gamma (GM) or dispersion (DM) models could also have been used; the $\operatorname{GM}(\alpha=3)$ and $\operatorname{DM}\left(\mathrm{D}_{\mathrm{P}}=0.22\right)$ models produce ${ }^{3} \mathrm{H}$ vs MTT trends that are closely equivalent to the $\mathrm{EPM}(\mathrm{f}=0.7)$ model (Stewart et al., 2017). Cartwright et al. (2018) showed that numerical models that include dispersion yield similar curves; such models are independent of the lumped parameter model approach.

The EPM model curve for Trier (Fig. 1a) is relatively flat because of the combined effects of radioactive decay and mixing. At present (2020), water with an MTT of 0 years has a mean tritium activity of about $8.2 \mathrm{TU}$, and this falls gradually to 5.5 TU for water with an MTT of 10 years. Water with greater MTTs then has slightly increased tritium activities with a maximum of 7.1 TU for water with MTTs of 50-60 years, due to the presence of increasing proportions of remnant bomb tritium. This means that only water with MTTs up to a maximum of 10 years can be identified in principle by tritium at present, i.e. there is a capacity for detecting water with MTTs of $0-10$ years because of the difference in ${ }^{3} \mathrm{H}$ activities of up to $2.7 \mathrm{TU}$, but water with longer MTTs will not be distinguishable from younger water with tritium at present. The precipitation record also shows a significant seasonal variation (approximately $8 \mathrm{TU}$ peak-to-peak) due to leak of tritium from the stratosphere each spring. This has not previously been used for dating (until Visser et al., 2019 and Rodriguez et al. 2021), however, the fact that this variation is seasonal and considerably larger than the long-term variation expected from the mixing model suggests that tritium will give results similar to those from the stable isotope seasonal variations, but with a small bias towards longer MTTs because of the small decrease of tritium activity between waters with MTTs of 0 and 10 years (in 2020) due to radioactive decay. 
Another study that determined the TTD using seasonal variation of tritium along with radioactive decay via the method of StorAge Selection functions was that of Visser et al. (2019). They also applied the method to ${ }^{18} \mathrm{O},{ }^{35} \mathrm{~S}$, and ${ }^{22} \mathrm{Na}$.. Their reconstructed tritium input (their Fig. S4.1), shows the high NH bomb peak similar to the Trier input in Fig. 1a, but tritium concentrations in rainfall fell much more rapidly after the tritium bomb pulse because of the influence of moisture from the Pacific Ocean (as also shown by Michel, 2006 and Stewart et al., 2012). Visser et al. found that tritium in precipitation was flat from 1990 to 2020, and therefore that radioactively decayed tritium reached its lowest level in 1990 before rising because of the high NH bomb pulse. This means that tritium can be used more effectively at present for identifying old water (with MTTs up to 30 years) in the southern Sierra Nevada and west coast of the United States than in western Europe, but the 1960s bomb pulse is a problem for both. The reconstructed southern Sierra Nevada record also has a substantial seasonal variation of 9.5 TU peakto-peak.

In summary, tritium concentrations currently have limited capacity to reveal old waters in $\mathrm{NH}$ catchments because of the presence of the remnant bomb tritium pulse from the 1960 's. It is difficult to see older water using ${ }^{3} \mathrm{H}$ now (especially when only short periods of measurements are available), however, post-bomb pulse conditions are considerably different in different parts of the $\mathrm{NH}$ (as shown by the different shapes of the tritium input functions for Trier and southern Sierra Nevada). The situation is gradually improving because bomb tritium is decaying and becoming further away in time. Samples collected now will be valuable in combination with samples collected in the future but relatively long series may be necessary. The 2030 EPM curve (Fig. 1a) shows the behaviour expected for samples collected in 2030 for central Western Europe. ${ }^{3} \mathrm{H}$ activities decrease from 8.2 to 3.8 TU for water with MTTs up to 20 years, but then the curve is flat at $3.8 \mathrm{TU}$ for longer MTTs. This will give better potential for identifying water with MTTs up to 20 years however.

In contrast, for waters collected in 2020 in Kaitoke in the Southern Hemisphere (Fig. 1b) there is a simple decline

in ${ }^{3} \mathrm{H}$ activities with MTT (from $1.9 \mathrm{TU}$ at 0 years to $0.46 \mathrm{TU}$ at 60 years) and the decrease continues to higher MTTs (not shown). This means that the determination of water TTs is only limited by analytical techniques (and is conservatively 100 years). The precipitation record also shows a seasonal variation of $1 \mathrm{TU}$ peak-to-peak which affects the EPM model curve at young MTTs and can in principle be used to determine young MTTs by the smoothing effect as with stable isotopes. Fig. $1 \mathrm{~b}$ also shows a portion of the 2030 EPM model curve which is a slightly steeper version of the 2020 curve.

\section{Evidence that ${ }^{3} \mathrm{H}$ TTDs can be different from ${ }^{2} \mathrm{H}$ TTDs}

After the bomb tritium pulse in the 1960s, Northern Hemisphere precipitation became enriched with tritium which could in principle and in fact was effectively traced through hydrological systems (Fig. 1a). Tritium studies from this period (1960-1990) showed that the TTDs of catchments covered a wide range of values (cited in Stewart et al., 2010). Estimated MTTs ranged from less than one year to decades (e.g. of the catchments listed in Stewart et al. (2010), 45\% had tritium MTTs of 0-5 years, 41\% had MTTs of 5-20 years and 14\% had MTTs greater than 20 years). Because MTTs deduced from stable isotope/chloride measurements are based on short-term (seasonal) variations which are fully or partially attenuated after four years depending on the mixing model applied, MTTs 
greater than about four years are difficult to substantiate (Stewart et al., 2010). If the MTTs were in fact longer than four years, they would tend to look like four years or less according to stable isotopes. So a large fraction of the catchments (up to 55\%) would have had very different MTTs when evaluated with tritium or with stable isotopes.

The Southern Hemisphere reached the stage of having problems with interpretation of tritium synchronously with the Northern Hemisphere, but the problem began to decrease much sooner in the SH (about 1990, see Fig. 1b) because of the c100 times smaller bomb pulse in the SH. The current situation allows for the effective use of tritium for estimating TTDs in SH catchments and the environment continues to become more favourable for the use of tritium.

A recent summary of tritium results from Australian catchments illustrates the capacity of tritium to identify old water in SH catchments (Table 1, Cartwright et al., 2020; Duvert et al., 2016). These MTTs are much longer than could be estimated by stable isotopes, so they show that the truncation issue is very much alive. The measurements cover both baseflow and high flow conditions (e.g. the Ovens Catchment measurements spanned Q8 to Q85 flows, and the LaTrobe and Gellibrand measurements Q10 to Q95 flows), implying that the truncation issue applies to both baseflow and high flows.

Table 1: MTTs for Australian catchments based on tritium

\begin{tabular}{ccc}
\hline Catchment & Baseflow (years) & High flow (years) \\
\hline Ovens $^{1}$ & $9-30$ & $4-10$ \\
Yarra $^{1}$ & $20-50$ & $13-37$ \\
LaTrobe $^{1}$ & $18-41$ & $7-19$ \\
Gellibrand $^{1}$ & $14->100$ & $7-20$ \\
Deep Creek $^{1}$ & $2-6$ & $<1-38$ \\
Lyrebird $^{1}$ & $45-50$ & $9-10$ \\
Teviot Brook $^{2}$ & $17 \pm 6$ & $38 \pm 15$ \\
\hline
\end{tabular}

${ }^{1}$ Cartwright et al. (2020) ${ }^{2}$ Duvert et al. (2016)

Rodriguez et al. (2021) have suggested that the differences between tritium and stable isotope MTTs in the literature could be attributed to methodological problems with the use and interpretation of tritium.

Methodological problems they identified included:

1. Sampling differences in streams - tritium concentrations have typically been determined at far less frequency and flow diversity (often only at baseflow) than stable isotopes, whereas stable isotope studies are becoming increasingly intensive and average over the full range of streamflows. However, that is not the case for the Australian studies that have estimated MTTs at a range of streamflows.

2. TTD assumptions - tritium studies have often assumed steady-state TTDs based on analytical expressions, whereas more recent stable isotope studies have used time-variable TTDs which cannot be expressed analytically

3. Methodology - tritium studies have used simpler mathematical formulations not involving antecedent rainfall and evapotranspiration except occasionally in recharge models, whereas stable isotope studies are now more commonly incorporating these elements via StorAge Selection function methods.

While these observations are valid, they do not alter the fundamental point that tritium in the right conditions can identify the presence of older water whereas stable isotopes cannot. Because tritium decays, the MTT can be 
indicated by reduction in tritium activity over time and not just by attenuation of seasonal tracer variability in the input signal.

\section{Discussion and Conclusions}

The situation in both hemispheres has changed in time as bomb pulse tritium has worked its way through the systems. In the Northern Hemisphere, tritium was useful for determining TTDs for a few decades past the bomb peak (1960s to 1980s). Then as the bomb tritium pulse decayed, single tritium measurements gave unclear and ambiguous TTD results, so that series of measurements were needed. This is still the case, but the NH is slowly emerging from this period. In the Southern Hemisphere, this ambiguous period was shorter and tritium is now effective for determining long TTs in catchments. Because estimates of TTDs can be made from single tritium measurements (provided the form of the TTD can be reasonably determined), no issue of time-variability arises since tritium can be (and has been) measured at any streamflow of interest.

185

In addition, to the long-term variations of tritium concentrations due to the bomb tritium pulse and radioactive decay, tritium shows medium-term, short-term (seasonal) and probably even shorter-term (e.g., between different rainfall events) variations. These are largely unexplored (as pointed out by Rodriguez et al. (2021)). The seasonal variations are increasingly prominent because tritium in precipitation is at background levels (except where tritium from local nuclear industry is present). This seasonal and event-scale tritium variation contains the same information as the variation of stable isotopes. Indeed Rodriguez et al. (2021) have shown that tritium is as effective as stable isotopes when used to determine TTDs from seasonal fluctuations (albeit more expensive). However, we feel that the real strength of tritium in comparison with stable isotopes is for determining longer TTs in catchments; at present and for some time into the future in the Northern Hemisphere, this will require widely spaced measurements in time. For this reason, it seems unreasonable to us to consider very detailed sampling of tritium on the scale of stable isotopes over short periods (unless tritium becomes measurable much more cheaply sometime in the future). Instead our recommendation is that more widely spaced measurements in time are favoured. Eventually, stream TTDs globally will be able to be estimated from single tritium measurements (representing TTDs at particular streamflows).

Author contributions. MKS prepared the first draft after discussion with UM. Substantive additions and edits were made by IC.

Competing interests. The authors declare that they have no conflict of interest. 


\section{References}

Benettin, P., Soulsby, C., Birkel, C., Tetzlaff, D., Botter, G., and Rinaldo, A.: Using SAS functions and highresolution isotope data to unravel travel time distributions in headwater catchments, Water Resources Research, 53, 1864-1878, http://doi.wiley.com/10.1002/2016WR020117, 2017.

Botter, G., Bertuzzo, E., and Rinaldo, A.: Catchment residence and travel time distributions: The master equation, Geophysical Research Letters 38, L11403, doi:10.1029/2011GL047666, 2011.

Cartwright, I., Morgenstern, U., Howcroft, W., Hofmann, H., Armit, R., Stewart, M., Burton, C., and Irvine, D.: The variation and controls of mean transit times in Australian headwater catchments. Hydrological Processes 34(21), 4034-4048. doi.org/10.1002/hyp.13862, 2020.

Cartwright, I., Irvine, D., Burton, C., and Uwe Morgenstern, U.: Assessing the controls and uncertainties on mean transit times in contrasting headwater catchments. Journal of Hydrology, 557, 16-29, https://doi.org/10.1016/j.jhydrol.2017.12.007, 2018.

Duvert, C., Stewart, M.K., Cendón, D.I., Raiber, M. 2016: Time-series of tritium, stable isotopes and chloride reveal short-term variations in groundwater contribution to a stream. Hydrology and Earth System Sciences 20, 257-277. doi:10.5194/hess-20-257-2016

IAEA and WMO: Global Network of Isotopes in Precipitation. The GNIP Database, https://nucleus.iaea.org/wiser, 2020.

Maloszewski, P., Rauert, W., Stichler, W., and Herrmann, A.: Application of flow models in an alpine catchment area using tritium and deuterium data. Journal of Hydrology 66, 319-330, 1983.

Maloszewski, P., and Zuber, A.: Determining the turnover time of groundwater systems with the aid of environmental tracers, 1. Models and their applicability. Journal of Hydrology 57: 207-231, 1982.

McGuire, K.J, and McDonnell, J.J.: A review and evaluation of catchment transit time modelling. Journal of Hydrology 330, 543-563, 2006.

Michel, R.L.: Tritium deposition in precipitation in the United States since August 1953. Unpublished manuscript, U.S. Geological Survey, 2006.

Morgenstern, U., Stewart M. K., and Stenger, R.: Dating of streamwater using tritium in a post nuclear bomb pulse world: continuous variation of mean transit time with streamflow. Hydrology and Earth System Sciences 14, 2289-2301, 2010.

Morgenstern, U., and Taylor, C.B.: Ultra low-level tritium measurement using electrolytic enrichment and LSC. Isotopes in Environmental and Health Studies 45: 96-117, 2009.

Pfister L., Martínez-Carreras N., Hissler Ch., Klaus J., Carrer, G., Stewart M.K., McDonnell J.J. 2017: Bedrock geology controls on catchment storage, mixing, and release: A comparative analysis of 16 nested catchments. Hydrological Processes 31, 1828-1845. DOI: 10.1002/hyp.11134, 2017.

Rodriguez, N.B., Pfister, L., Zehe, E., and Klaus, J.: A comparison of catchment travel times and storage deduced from deuterium and tritium tracers using StorAge Selection functions. Hydrology and Earth System sciences 25, 401-428, 2021. doi: 10.5194/hess-25-401-2021

Schmidt, A., Frank, G., Stichler, W., Duester, L., Steinkopff, T., and Stumpp, C.: Overview of tritium records from precipitation and surface waters in Germany. Hydrological Processes 34, 1489-1493. DOI: 10.1002/hyp.13691, 2020. 
https://doi.org/10.5194/hess-2021-146

Preprint. Discussion started: 1 April 2021

(c) Author(s) 2021. CC BY 4.0 License.

Stewart, M. K., Morgenstern, U., and McDonnell, J. J.: Truncation of stream residence time: how the use of stable isotopes has skewed our concept of streamwater age and origin, Hydrological Processes, 24, 1646-1659, https://doi.org/10.1002/hyp.7576, 2010.

Stewart, M.K., Morgenstern, U., Gusyev, M.A., and Maloszewski, P.: Aggregation effects on tritium-based mean transit times and young water fractions in spatially heterogeneous catchments and groundwater systems. Hydrology and Earth System Sciences 21, 4615-4627, doi:10.5194/hess-21-4615-2017, 2017.

Stewart, M.K., Morgenstern, U., McDonnell, J.J., and Pfister, L.: The 'hidden streamflow' challenge in catchment hydrology: A call to action for streamwater transit time analysis. Invited Commentary, Hydrological Processes 26(13), 2061-2066. doi: 10.1002/hyp.9262, 2012.

Visser, A., Thaw, M., Deinhart, A., Bibby, R., Safeeq, M., Conklin, M., Esser, B., and Van der Velde, Y.: Cosmogenic isotopes unravel the hydrochronology and water staorage dynamics of the Southern Sierra critical zone. Water Resources Research 55, 1429-1450. Doi:org/10.1029/2018WR023665, 2019. 